\title{
Pathogenicity of Salmonella During Schistosoma-Salmonella Co-infections and the Importance of the Gut Microbiota
}

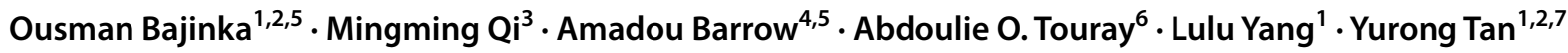

Received: 26 May 2021 / Accepted: 21 October 2021 / Published online: 14 December 2021

(c) The Author(s), under exclusive licence to Springer Science+Business Media, LLC, part of Springer Nature 2021

\begin{abstract}
Antibiotic inefficacy in treating bacterial infections is largely studied in the context of developing resistance mechanisms. However, little attention has been paid to combined diseases mechanisms, interspecies pathogenesis and the resulting impact on antimicrobial treatment. This review will consider the co-infections of Salmonella and Schistosoma mansoni. It summarises the protective mechanisms that the pathophysiology of the two infections confer, which leads to an antibiotic protection phenomenon. This review will elucidate the functional characteristics of the gut microbiota in the context of these co-infections, the pathogenicity of these infections in infected mice, and the efficacy of the antibiotics used in treatment of these co-infections over time. Salmonella-Schistosoma interactions and the mechanism for antibiotic protection are not well established. However, antimicrobial drug inefficacy is an existing phenomenon in these co-infections. The treatment of schistosomiasis to ensure the efficacy of antibiotic therapy for bacterial infections should be considered in co-infected patients.
\end{abstract}

\section{Graphical Abstract}

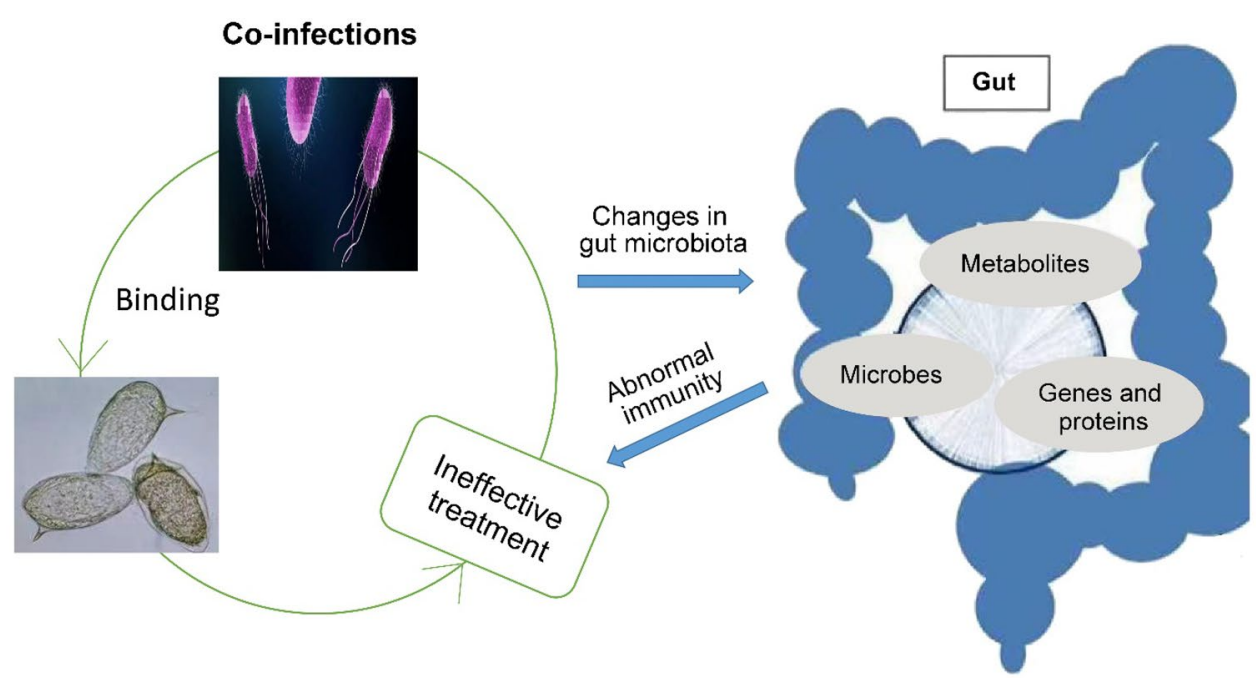

Co-infections of Salmonella and Schistosoma mansoni confers the protective mechanisms that give ineffetive treatment of salmonella. The functional characteristics of the gut microbiota in the context of these co-infections influence the pathogenicity of the both pathogens thereby drecreasing immunity and brings changes in gut metabolism.

Yurong Tan

yurongtan@csu.edu.cn

Extended author information available on the last page of the article

\section{Introduction}

The severeity and treatment efficacy of schistosomiasis on bacterial, viral or other parasitic co-infections has a growing concern. Among the much studied are cases of Salmonella infection during schistosomiasis. Co-infections of 
Schistosoma and hepatitis B or C, malaria, leishmaniasis and HIV aslo are under study [1]. Moreover, Schistosoma as co-infection with other protozoa, with helminths and with bacteria other than Salmonella are also been studied [2]. Co-infections with Schistosoma and Salmonella confound the clinical picture of both diseases. Evidence emerging from in vitro [3, 4], animal model experiment [5] and clinical observations [6] regarding the symbiotic relationship existing between Schistosoma and Salmonella showed efficacy in the drug administered for treatment is only optimal when concurrent anti-Schistosomal therapy is administered. Although number of studies centred on the study of the concurrent Schistosoma-Salmonella infections, their complicated mechanisms where bacteria adhere to the adult Schistosomes present in the mesenteric vasculature require further research [3]. The pathogenicity of S. mansoni, alteration in host gut microbiota, and the evolution of drug resistance in concurrent Schistosoma-Salmonella infections in vitro and in vivo is yet to shed light on the pathogenicity of the two pathogens that might give rise to the evolution of antibacterial drug resistance [7]. To this end, the phenomena that give rise to persistent Salmonella enterica serovar Typhimurium bacteraemia or bacteriuria in the presences of $S$. mansoni will be explored in this review. The paper will investigate these synergistic effects of schistomiasis and salmonellosis as a co-infectoin.

The most common bacterial genus causing foodborne infections is Salmonella. They infect wide range of hosts including human and bird species [8]. Worldwide, the various serovars of Salmonella spp. are known as a water and food borne gastrointestinal pathogens, and a systemic diseases pathogen. Typhoid fever alone is estimated at 10.9 million cases annually, most in low- and middle-income countries [9]. In each year, 129.5 million cases of non-typhoidal Salmonella (NTS) human cases give between 100,000 and 1 million deaths worldwide [9]. With more than 2600 serovars, Salmonella enterica subspecies enterica infections are a persistent public health burden, among animals and food industry[10]. The pathogen is transmitted through contamination of food, water and fomites. Some serovars are species-specific but the vast number are "host-adapted" (broad host spectrum) serovars [8].

It is estimated that, 230 million people from the 74 developing tropical and subtropical countries are infected by schistosomiasis yearly. 200,000 deaths are recorded per year [11]. Furthermore, there are number of asymptomatic cases and those with the appearance of symptoms. Asymptomatic infections represent approximately $16.7 \%$ of the 120 million affected persons [11].

In human, the clinical manifestations of schistosomiasis are in three phase and these are; acute, sub acute and chronic stages. Once the matured parasite settled in the targeted organs, for example, in the lower urinary tract with
Schistosoma haematobium and the other spieces in colon and rectum, it develop into secondary manifestations, which happens in liver, lungs, kidneys etc. The healing of granulomata by fibrosis and calcification in the renal glomeruli by deposition of schistosomal antigen-antibody complexes, the development of secondary amyloidosis or at the sites of oval entrapment are attributed to chronic morbidity [1]. Based on the immune response, the clinical manifestations of schistosomiasis full under acute, sub-acute and chronic stages. The acute stage (Katayama fever) is species-specific is seen during the early invasion and migration [12]. During the log phase of parasite growth curve, granulomata around the eggs are formed. Immunity is seen during the chronic stages of disease. During this stage, the pathogen will gain an upper hand against innate, TH1 and TH2 adaptive cells [1]. Complications are seen among some patients. Co-infections or associated pathogenic agents will persist and this condition avails salmonella diseases treatment inefficacy [2]. Inflammation, liver fibrosis, micro abscess formation, ulceration, polyposis and hyperplasia are abnormal physiological functions induce by Schistosoma ova [13]

\section{Treatment Options}

Salmonella enterica serotypes Typhi and Paratyphi and Typhimurium may persist in the gut, causing ineffective antibiotic treatment and subsequently antimicrobial resistance [14]. Eradication and treatment of salmonellosis is becoming complicated by the emergence of multi-drug resistance (MDR) Salmonella spp. [15]. Increasing antibiotic-resistance in strains of Salmonella are an increasing infection, public health and economic burden in SSA [16]. In addition to the resistant strains, antibiotics disrupt the gut microbiota and the persisting antibiotic-induced diarrhoea promotes the reduction of benign bacterial population that produce the protective short chain fatty acids (SCFAs). SCFAs are required for various energy supplies such as colon cell proliferation and differentiation by Butyrate [17]. To curb this situation, alternative treatments options are required. The supplementation of probiotic-organisms seems promising. However, the strain and organism type used as probiotic might encourage the growth of opportunistic pathogens. Furthermore, antibiotic susceptibility and antibiotic-resistant carriers are other phenomenal issues associated with probiotic complementary therapy. To this end, a holistic study on probiotic mechanisms and their efficacy is needed [18].

The current state in the treatment of salmonella infections does not look promsing. Although the burden of infectious disease lies in the least developed countries, routine surveillance for antimicrobial resistance is not robust. For instance, NTS is now taken to be $50-70 \%$ MDR, including resistance to flouroquinolones and 3rd generation cephalosporins. 
Furthermore, fluoroquinolones, which is the choice for MDR cases are not effective in treating Salmonella Typhi and Salmonella Paratyphi A [19]. Chloramphenicol, ampicillin and co-trimoxazole are also ineffective leaving quinolones as a choice to treat MDR Salmonella [20]. Kanamycin with an enhanced MDR Salmonella swarming properties on number of isolates is a promising treatment strategy [21]. Due to the poor economic status and inadequate resource in subSaharan Africa, the prudent use of effective antimicrobials looks unrealistic [19]. What this review will recommend is the typhoid vaccines and hope that there will be acceleration of trials for novel iNTS vaccines [19]. Again, a radical and aggressive approach is the only way to establish rational use of antibiotics during treating infections [20].

The preventive measures for schistosomiasis will not be effective without effective education and periodic mass treatment. The implementation of chemical mollusciciding-based control of Bulinus and Biomphalaria spp., snails is proven effective. With the elimination of these intermediate hosts, local transmission is drastically reduced, albeit incomplete. S. mansoni and S. haematobium transmission are minimized even in the in high risk areas [22]. Praziquantel as the drug of choice has $80 \%$ cure rate and can only be supplemented with effective vaccine for absolute eradication of schistosomiasis [2]. However, for fibrotic lesions, surgical treatment is the last resort. In effective reduction of infection intensity, Praziquantel $40 \mathrm{mg} / \mathrm{kg}$ is reccomended among preschooland school-aged children [23]. To elicit a mucosal response, attenuated $S$. Typhimurium strain (YS1646) is produce as multi-modality vaccine. This intervention is targeting Cathepsin B (CatB) is a promising intervention for complete protection against $S$. mansoni [24]. Schistosoma vaccine development is promised on oral delivery of the antigen by nirB-driven $S$. Typhimurium type III secretion system [25].

\section{Schistosoma and Salmonella Co-infections}

Dual Schistosoma and Salmonella infection is a public health challenge and other schistosomiasis endemics. The interactions of Schistosoma and Salmonella is favorred by the immunosuppression of the host due parasitic infections [26]. As both are water-borne human pathogens common in areas with poor sanitation, the co-existence of Schistosomes and Salmonella infections is a common occurence. The type of organisms involved, order and time of interval between the infections, the pedigrees of the parasites, infectious agents are all associating factors that appear to determine the synergistic pathogenicity of the co-infection [2]. Another confounding factor in the study of Schistosoma co-infection is the prior infection with Schistosoma, which has effects on the subsequent infection. With this prior infection, the severity of subsequent infection with Fasciola hepatica, Plasmodium, Echinostoma or Helicobacter pylori is decreased [2]. In contrast to Toxoplasma gondii,
Leishmania, Staphylococcus aureus, Entamoeba histolytica or Salmonella, the subsequent infection appear to present in a more severe form with a prior infection with Schistosoma [2]. Co-infection is projected to be increasingly associated with the prevalence uncomplicated $P$. falciparum infection in children. However, an interesting reduction of haemoglobin level in high density P. falciparum infection was observed [27].

\section{Medical Importance of Co-infections}

The incidence of high morbidity and mortality of helminth infections come with intracellular pathogens such as Salmonella. Prolonged fever and enlarged liver and spleen are some clinical manifestation associated with co-infections, in addition to chronic septicemic salmonellosis. These are seen with patients with Salmonella-Schistosoma co-infections [28]. Conversely, complicated persistent Salmonella urinary tract infection was found to be associated with urinary schistosomiasis [28]. Schistosoma-Salmonella co infections lead a chronic septicemic salmonellosis. In addition to higher bacterial load, this co-infection will first impair IFN- $\gamma$ and IL-17 responses. This is faciliated via basophils recruition by a glycoprotein secreted live schistosome eggs (IPSE/ alpha-1). IPSE/alpha-1 will trigger IL-4 and IL-13 release from basophils and the overall immunoregulatory activities are studied to give a prolong fever and enlargement of liver and spleen [14].

\section{Pathogenicity of Co-infection}

The co-infection of Schistosoma with $S$. Typhimurium can ameliorate schistosomiasis in the metabolic alterations associated with infection since the host immune response is manipulated by the secondary bacterial infection [6]. Salmonella can evade the effects of antibiotics via adherence to Schistosomes (Table 1). Salmonella can attach to the outer cuticle of adult schisotosomes. In this state, are resistant to antibiotics via a protective mechanism [29]. The protective mechanism and proven treatment inefficiency is hypothesized to be the overall immunoregulatory activities of Schistosomes. These activities include induction of Tregs, Bregs degrades antibodies and alternatively activated macrophages [14]. In vitro design of study to qualitatively assess some common antibiotics has gathered evidence regarding Salmonella adhering to schistosomes.

\section{The Effects of Antibiotic Treatment on Co-infection}

\section{Antibiotic Protection}

In a bid to treat patients infected with Schistosomiasis, anthelmintic praziquantel (PZQ) is a common therapeutic drug. However, dysbiosis seems an effect associate with this 


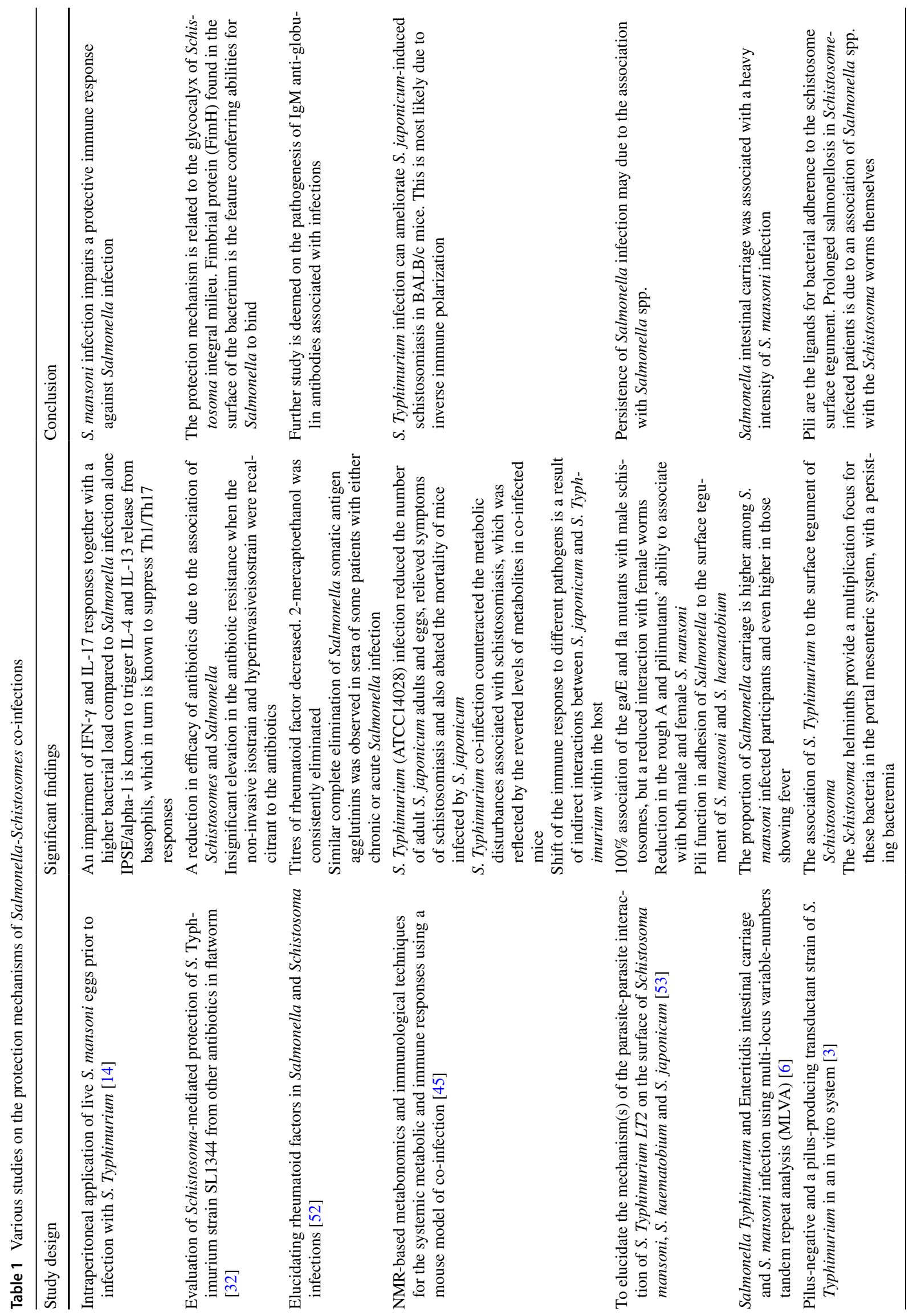


intervention. A shift in gut microbiota composition pre and post PZQ treatments was seen [30]. Although the gut bacterial population varies between people infected with schistosomiasis and those who do not, the abundance phyla were Bacteroides, then Firmicutes and Proteobacteria between the pre and post-treatment [31]. Furthermore, only limited variations in the relative abundance of taxa among bacterial classes and this variation is not affiliated to age or sex of the participants.

\section{Antibiotic Concentration Against Bacteria}

As a result of Schistosoma-associated Salmonella, the adherence of bacteria to the flatworm reduces the efficacy of antiobiotic treatments targeting those Salmonella. The concentrations of the antibiotic used during the in vitro antibiotic assay assessment against Salmonella-Schistosoma co-infection were studied to effect killing bacteria at a relative rate. Using a novel antibiotic protection assay, an absolute (100\%) efficacy of antibiotic (amoxicillin $(32 \mu \mathrm{g} / \mathrm{ml})$, cefepime $(32 \mu \mathrm{g} / \mathrm{ml})$, cefpodoxime $(32 \mu \mathrm{g} / \mathrm{ml})$, chloramphenicol $(32 \mu \mathrm{g} / \mathrm{ml})$, ciprofloxacin $(4 \mu \mathrm{g} / \mathrm{ml})$, streptomycin $(32 \mu \mathrm{g} /$ $\mathrm{ml})$, sulfadimethoxine $(512 \mu \mathrm{g} / \mathrm{ml})$, or tetracycline $(16 \mu \mathrm{g} /$ $\mathrm{ml}$ ) was seen with Salmonella strains incubated alone, while a decreased efficacy of less than $12 \%$ of the same strains when incubated with adult Schistosoma mansoni [32]. This protective mechanism is in contrast to the hypothesis that arises on the basis of the virulent nature of the strain type of Salmonella. Specific fimbrial protein (FimH) present on the surface on the bacterium confers binding to Schistosomes. When both invasive strains and non-invasive strains of Salmonella typhimurium were incubated with Schistosomes mansoni under the same amoxicillin concentration $(32 \mu \mathrm{g} /$ $\mathrm{ml}$ ), the protective mechanism against the effects of amoxicillin enables the bacteria to live. Based on concentration on co-incubation with the control free-living flatworm Girardia tigrina and with Hep-2 mammalian tissue culture cells showed no replication of this protective mechanism. Unlike Salmonella spp., Escherichia coli did not benefit from the protective mechanism of attachment to schistosomes [32]. In order to achieve therapeutic levels or treatment efficiacy of the antibiotic used in co-infections study, perturbing the binding mechanism to schistosomes is required to eliminate Salmonella [32].

\section{Antimicrobial Treatment Failure Due to Co-infections}

It is ascertained that any ineffective use of antibiotics may result in resistance gene acquisition and expression [32]. Salmonella factors facilitate the attachment to Schistosoma and they catalogued the antibiotics that are infective against the co-infection [32]. Schistosoma-Salmonella co-infections are as a result of the enteroinvasiveSalmonella entering the systemic circulation whereby the Salmonella attach to the tegument of adult Schistosoma in the mesenteric vasculature $[4,5,33]$. In a normal Schistosoma infected patient, the anthelmintic praziquantel is a key choice of therapy. However, in cases of Schistosoma-associated Salmonella, such therapy is observed to cause a massive release of Schistosoma-associated Salmonella, leading to acute septicaemia among children when Salmonella treatment options are not co-administered [34, 35].

\section{Salmonella Interactions with the Microbiome}

Salmonella infection in a mouse model has been seen to drastically alter the homeostasis of gut microbiota and thus the intestinal metabolome. The physiological functions and hormone metabolism were significantly altered [36]. $S$. Typhimuriumis is a prominent competitor with commensal gut microbiota. Once they dominate the gut microbiota population, their invasion signals the onset of infection. Both intestinal and urinary schistosomiasis will also alters the gut microbiome (Table 2).

\section{Microbiome and Co-infection}

Commensal microorganisms called gut microbiota are vast number of organism living gastrointestinal (GI) tract of vertebrates. Their functions range from maintenance of energy balance, nutrition and host immunity [37], and the production of antimicrobial products, bacteriophages deployment and enhancing gut barrier integrity [38]. A healthy gut microbiome is a critical defence against colonization of pathogenic or exogenous microorganisms. This effect is referred to as colonization resistance (CR) and helps to minimize exogenous pathogens, which many colonize the gut and ultimately cause infection [36]. An imbalance of these dysbiosis is associated with number of chronic and autoimmune disorders [39]. Besides environmental factors, macrobiota including parasitic helminths with their pathogenic effects including metabolic activity, immune system and lead to infection [36]

Of recent, the role of gut microbiome is shedding more lights to health of host and the functions not limited to are the biochemical, immunological and nutritional response of the gut microbiome are more a less biomarkers [40]. To add scholarly evidence to the existing and emerging theories, this review will create literature for a futher study to investigate the role of the gut microbiome in parasitic infection, co-infections, and the antibiotic resistance due to the pathology. The acquired immunity among patients when exposed to helminths, aggravated with bacterial infections and the resulting immune response to the concurrent infections [41, 42]. In a bid to assess the impact of sequential infection of 


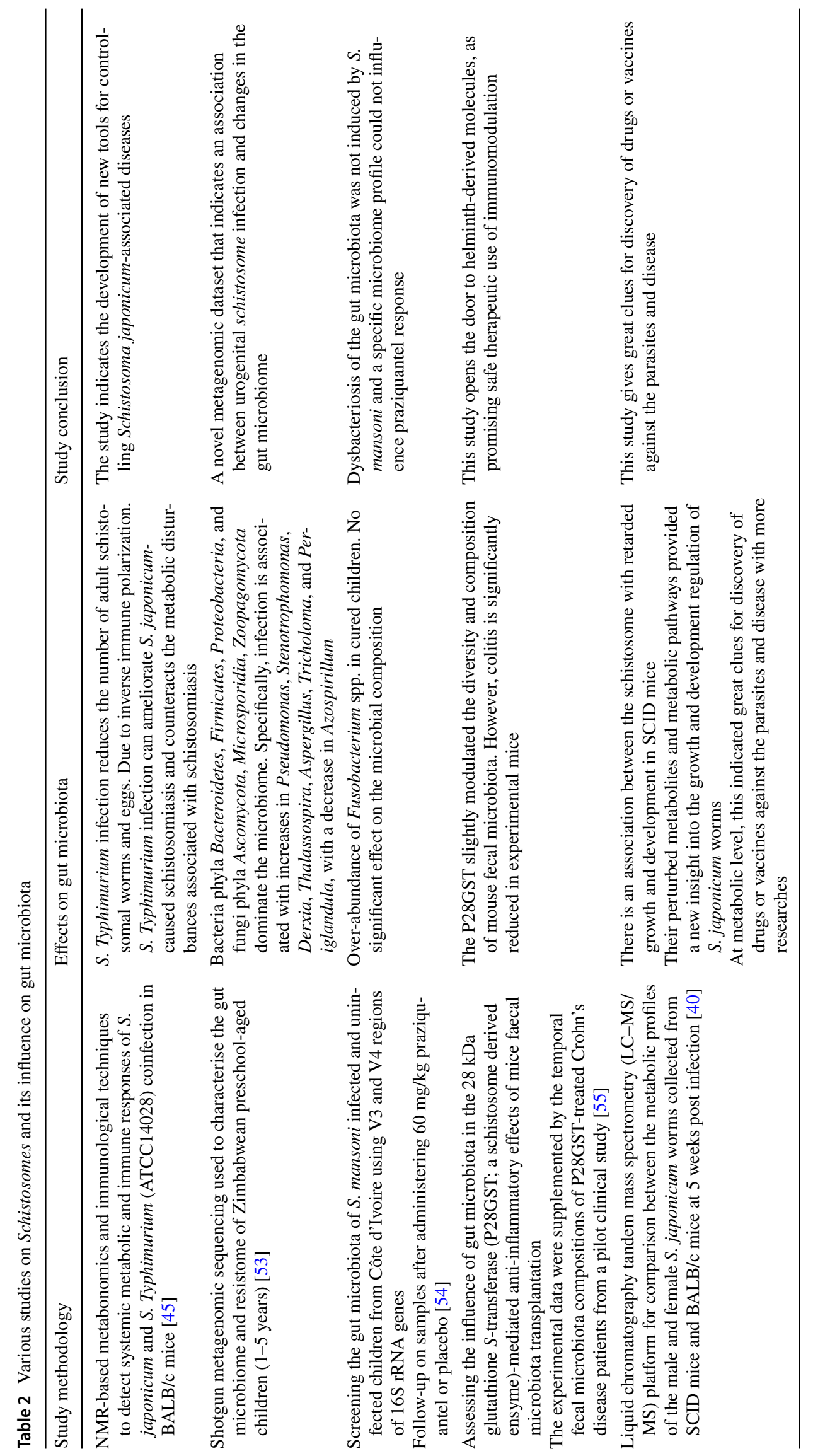


bacteria and helminths on the host, this reviewisvowed to consider the co infection of $S$. Typhimurium and $S$. mansoni.

\section{Metabolic Response to the Co-infection}

Metabolomics has been a robust tool in studying metabolic response to series of stimuli and one such is a co-infection [43]. Chromatography coupled to mass spectrometry or $1 \mathrm{H}$ nuclear magnetic resonance (NMR) spectroscopy, with the multivariate statistical analysis aid to determine metabolic changes in system response to stress or stimuli [44]. Alternative therapeutic such as personalized medicine based on microbiome might get its roots from the effects of Salmonella in the co-infection provided that, the salmonella serotype is non-invasive and non-pathogenic.

Using the NMR-based Metabolomics and immunological techniques to detect the systemic metabolic and immune responses, respectively, this study concluded Salmonella enterica serovar Typhimurium effects reduction in egg counts and the number of adult worms and relieves symptoms of schistosomiasis [45]. The metabolic disturbance of co-infected mice was compared with $S$. japonicum, reverted levels of metabolites result from the former infection. Due to inverse immune polarization; the bacteria have been seen to ameliorate $S$. japonicum induced schistosomiasis in BALB/c mice [45]. In order to explore on this pathogenicity, other forms of Schistosoma should be studied in co-infection with the same serotype of Salmonella.

\section{Immune Response to the Co-infection}

A shift in host immune response from Th1 to Th2 polarization is studied to be an effect of Schistosoma infection of a typical schistosomiasis [45]. The alteration is achieved due to the progress of the disease including cercariae intrusion, migration of larvae, pairing in adult and laying of eggs [46]. Unlike Schistosoma, infection caused by $S$. Typhimurium only induces Th1 polarization [47]. The clinical significance of the host immune impairment by the combined effects of the $S$. Typhimurium and $S$. mansoni could draw much attention to the interaction between these two species. One instance is the influence of gut microbiota on the generation of Th17 cells. The effector lineage of CD4 T cells with protective abilities against inflammatory and harmful autoimmune conditions are Th17 cells [48]. They mobilize host immunity against microbial pathogens such as Salmonella [49]. Expansion of segmented filamentous bacteria (SFB) is also inhibited with an increase in $\alpha$-defensin expression of IL-17. Low number of IL-17-producing Th17 cells in the lamina propria signals loss of $\alpha$-defensin and expansion of SFB [50]. While much attention is paid on bacterial benefits to the host immunity, benign worms and viral species are yet to be explored.

\section{Future Research}

Salmonella resistant to multiple antimicrobials worldwide is a threat to global health. The emerging of clones of resistant strains even in the under developed world requires a holistic approach on food chain and distribution system [51]. An improved understanding of the impact of genome variation of bacterial pathogens on pathogen-host and pathogen-environment interactions has the potential to improve quantitative risk assessment and reveal how new pathogens evolve [10]. The physical barrier theory of mammalian cell-docking site for FimH protein [32], begs for a further study despite it is ascertained that the resistance is transient and is observed only during adherence.

The efficacy of antibiotics will be determined by the weekly faecal culture for bacteria responsible for urinary tract infections and stomach disorders. Such study is hoped to ascertain the body's immune response to $S$. mansoni infection in co-infection. This will be based on the granulomatous reaction involving $\mathrm{T}$ cells, macrophages, and eosinophil of group of antibiotic and non-antibiotic interventions and on the Schistosoma weekly egg counts through time. With respect to in vitro study, novel antibiotic protection assay of antibiotic-sensitive, Salmonella strains are ought to be developed, incubated with a known concentration of effective therapeutic proven antibiotic. In sense, the lethal dose should be $100 \%$ effective to eliminate Salmonella strains in the void of concurrent Salmonella infections [3].The study of co-infections involving Schistosoma and Salmonella should be based on model that will explain a wholesome range of parameters. Study of the mucosal cell gene expression, innate and adaptive mucosal immune responses, the virulence expressed by the pathogens involved, microbiota gene expression and the genetic profiling of the host will confer clear explanation to the homeostasis [37].

\section{Conclusion}

In a bid to curb with the emerging infectious diseases in subSaharan Africa, much paid attention should be equally paid to the treatment inefficacy arising as a result of co-infection. These combined disease mechanism has ways to escaope antimicrobial treatment. We dwelled on co-infections of Salmonella and S. mansoni to ascertain the antibiotic protection phenomenon and functional characteristics of the gut microbiota. Salmonella-Schistosoma co-infections need more study to decipher on the exact phenomenon existing with regards to the pathogenicity. Establishing the protective mechanism conferred by schistosomes for Salmonella to survive antibiotic treatment are still not clear as per mechanism. 
Acknowledgements We acknowledge Dr Richard Bradbury for his guidance in designing and proofreading this review article.

Authors' Contributions OB wrote the paper, LY, MQ, AB AOT and YT proofread the paper.

Funding This work was supported by Grants 31771277 from National Natural Science Foundation of China.

Data Availability Not applicable.

\section{Declarations}

Conflict of interest The authors declare no conflict of interest.

Consent to Participate Not applicable.

Consent for Publication Not applicable.

Ethical Approval Not applicable.

\section{References}

1. Barsoum RS, Esmat G, El-Baz T (2013) Human schistosomiasis: clinical perspective: review. J Adv Res 4(5):433-444. https://doi. org/10.1016/j.jare.2013.01.005

2. Abruzzi A, Fried B (2011) Coinfection of Schistosoma (Trematoda) with bacteria, protozoa and helminths. Adv Parasitol 77:185. https://doi.org/10.1016/B978-0-12-391429-3.00005-8

3. Marege A, Seid M, Boke B, Thomas S, Arage M, Mouze N, Yohanes T, Woldemariam M, Manilal A (2021) Prevalence of Schistosoma mansoni-Salmonella coinfection among patients in southern Ethiopia. New Microbes New Infect 40:100842. https:// doi.org/10.1016/j.nmni.2021.100842

4. Hsiao A, Toy T, Seo HJ, Marks F (2016) Interaction between Salmonella and Schistosomiasis: a review. PLoS Pathog 12(12):e1005928. https://doi.org/10.1371/journal.ppat.1005928

5. Wilson RL, Elthon J, Clegg S, Jones BD (2000) Salmonella enterica serovars Gallinarum and Pullorum expressing Salmonella enterica serovar Typhimurium type 1 fimbriae exhibit increased invasiveness for mammalian cells. Infect Immun 68(8):4782 4785. https://doi.org/10.1128/IAI.68.8.4782-4785.2000

6. Mbuyi-Kalonji L, Barbé B, Nkoji G, Madinga J, Roucher C, Linsuke S, Hermy M, Heroes AS, Mattheus W, Polman K, Lutumba P, Phoba MF, Lunguya O, Jacobs J (2020) Non-typhoidal Salmonella intestinal carriage in a Schistosoma mansoni endemic community in a rural area of the Democratic Republic of Congo. PLoS Negl Trop Dis 14(2):e0007875. https://doi.org/10.1371/journal. pntd.0007875

7. Keren I, Shah D, Spoering A, Kaldalu N, Lewis K (2004) Specialized persister cells and the mechanism of multidrug tolerance in Escherichia coli. J Bacteriol 186(24):8172-8180. https://doi.org/ 10.1128/JB.186.24.8172-8180.2004

8. Jajere SM (2019) A review of Salmonella enterica with particular focus on the pathogenicity and virulence factors, host specificity and antimicrobial resistance including multidrug resistance. Vet World 12(4):504-521. https://doi.org/10.14202/vetworld.2019. 504-521

9. Birkhold M, Coulibaly Y, Coulibaly O, Dembélé P, Kim DS, Sow S, Neuzil KM (2020) Morbidity and mortality of typhoid intestinal perforation among children in sub-Saharan Africa 1995-2019: a scoping review. World J Surg 44(9):2892-2902. https://doi.org/ $10.1007 / \mathrm{s} 00268-020-05567-2$

10. Park CJ, Andam CP (2020) Distinct but intertwined evolutionary histories of multiple Salmonella enterica subspecies. mSystems. https://doi.org/10.1128/mSystems.00515-19

11. Lamas A, Miranda JM, Regal P, Vázquez B, Franco CM, Cepeda A (2018) A comprehensive review of non-enterica subspecies of Salmonella enterica. Microbiol Res 206:60-73. https://doi.org/ 10.1016/j.micres.2017.09.010

12. Bamgbola OF (2014) Urinary schistosomiasis. Pediatr Nephrol (Berlin, Germany) 29(11):2113-2120. https://doi.org/10.1007/ s00467-013-2723-1

13. WHO (2010) Salmonella. [http://www.who.int/mediacentre/facts heets/fs139/en/]

14. Schramm G, Suwandi A, Galeev A, Sharma S, Braun J, Claes AK, Braubach P, Grassl GA (2018) Schistosome eggs impair protective Th1/Th17 immune responses against Salmonella infection. Front Immunol 9:2614. https://doi.org/10.3389/fimmu.2018.02614

15. Kariuki S, Gordon MA, Feasey N, Parry CM (2015) Antimicrobial resistance and management of invasive Salmonella disease. Vaccine. https://doi.org/10.1016/j.vaccine.2015.03.102

16. Kariuki S, Mbae C, Van Puyvelde S, Onsare R, Kavai S, Wairimu C, Ngetich R, Clemens J, Dougan G (2020) High relatedness of invasive multi-drug resistant non-typhoidal Salmonella genotypes among patients and asymptomatic carriers in endemic informal settlements in Kenya. PLoS Negl Trop Dis 14(8):e0008440. https://doi.org/10.1371/journal.pntd.0008440

17. Akhtar S, Sarker MR, Jabeen K, Sattar A, Qamar A, Fasih N (2015) Antimicrobial resistance in Salmonella enterica serovar Typhi and Paratyphi in South Asia-current status, issues and prospects. Crit Rev Microbiol 41(4):536-545. https://doi.org/10.3109/ 1040841X.2014.880662

18. Brunelle BW, Bearson BL, Bearson S, Casey TA (2017) Multidrug-resistant Salmonella enterica serovar Typhimurium isolates are resistant to antibiotics that influence their swimming and swarming motility. mSphere. https://doi.org/10.1128/mSphere. 00306-17

19. Smith SI, Seriki A, Ajayi A (2016) Typhoidal and non-typhoidal Salmonella infections in Africa. Eur J Clin Microbiol Infect Dis 35(12):1913-1922. https://doi.org/10.1007/s10096-016-2760-3

20. Guarner F, Malagelada JR (2003) Gut flora in health and disease. Lancet (London, England) 361(9356):512-519. https://doi.org/ 10.1016/S0140-6736(03)12489-0

21. Gut AM, Vasiljevic T, Yeager T, Donkor ON (2018) Salmonella infection - prevention and treatment by antibiotics and probiotic yeasts: a review. Microbiology (Reading, England) 164(11):13271344. https://doi.org/10.1099/mic.0.000709

22. King CH, Sutherland LJ, Bertsch D (2015) Systematic review and meta-analysis of the impact of chemical-based mollusciciding for control of Schistosoma mansoni and S. haematobium transmission. PLoS Negl Trop Dis 9(12):e0004290. https://doi.org/10. 1371/journal.pntd.0004290

23. Zwang J, Olliaro P (2017) Efficacy and safety of praziquantel $40 \mathrm{mg} / \mathrm{kg}$ in preschool-aged and school-aged children: a metaanalysis. Parasit Vectors 10(1):47. https://doi.org/10.1186/ s13071-016-1958-7

24. Hassan AS, Zelt NH, Perera DJ, Ndao M, Ward BJ (2019) Vaccination against the digestive enzyme Cathepsin B using a YS1646 Salmonella enterica Typhimurium vector provides almost complete protection against Schistosoma mansoni challenge in a mouse model. PLoS Negl Trop Dis 13(12):e0007490. https://doi. org/10.1371/journal.pntd.0007490

25. Chen G, Dai Y, Chen J, Wang X, Tang B, Zhu Y, Hua Z (2011) Oral delivery of the Sj23LHD-GST antigen by Salmonella typhimurium type III secretion system protects against Schistosoma 
japonicum infection in mice. PLoS Negl Trop Dis 5(9):e1313. https://doi.org/10.1371/journal.pntd.0001313

26. Ashour DS, Othman AA (2020) Parasite-bacteria interrelationship. Parasitol Res 119(10):3145-3164. https://doi.org/10.1007/ s00436-020-06804-2

27. Degarege A, Degarege D, Veledar E, Erko B, Nacher M, BeckSague CM, Madhivanan P (2016) Plasmodium falciparum infection status among children with Schistosoma in sub-Saharan Africa: a systematic review and meta-analysis. PLoS Negl Trop Dis 10(12):e0005193. https://doi.org/10.1371/journal.pntd. 0005193

28. Chacha F, Mshana SE, Mirambo MM, Mushi MF, Kabymera R, Gerwing L, Schneiderhan W, Zimmermann O, Groß U (2015) Salmonella Typhi meningitis in a 9-year old boy with urinary schistosomiasis: a case report. BMC Res Notes 8:64. https://doi. org/10.1186/s13104-015-1030-2

29. He Y, Tang Y, Peng M, Xie G, Li W, Tan Z (2019) Influence of Debaryomyces hansenii on bacterial lactase gene diversity in intestinal mucosa of mice with antibiotic-associated diarrhea. PLoS ONE 14(12):e0225802. https://doi.org/10.1371/journal. pone. 0225802

30. Mekonnen A, Legesse M, Belay M, Tadesse K, Torben W, Teklemariam Z, Erko B (2013) Efficacy of praziquantel against Schistosoma haematobium in Dulshatalo village, western Ethiopia. BMC Res Notes 6:392. https://doi.org/10.1186/ 1756-0500-6-392

31. Gal-Mor O, Boyle EC, Grassl GA (2014) Same species, different diseases: how and why typhoidal and non-typhoidal Salmonella enterica serovars differ. Front Microbiol 5:391. https://doi.org/10. 3389/fmicb.2014.00391

32. Barnhill AE, Novozhilova E, Day TA, Carlson SA (2011) Schistosoma-associated Salmonella resist antibiotics via specific fimbrial attachments to the flatworm. Parasit Vectors 4:123. https://doi.org/ 10.1186/1756-3305-4-123

33. Gendrel D, Richard-Lenoble D, Kombila M, Engohan E, Nardou M, Moussavou A, Galliot A, Toure R (1984) Schistosoma intercalatum and relapses of Salmonella infection in children. Am J Trop Med Hyg 33(6):1166-1169. https://doi.org/10.4269/ajtmh. 1984.33.1166

34. Crump JA, Mintz ED (2010) Global trends in typhoid and paratyphoid Fever. Clin Infect Dis 50(2):241-246. https://doi.org/10. $1086 / 649541$

35. Agoston K, Kerékgyártó J, Hajkó J, Batta G, Lefeber DJ, Kamerling JP, Vliegenthart JF (2002) Synthesis of fragments of the glycocalyx glycan of the parasite Schistosoma mansoni. Chemistry (Weinheim an der Bergstrasse, Germany) 8(1):151-161. https:// doi.org/10.1002/1521-3765(20020104)8:1\%3c151::aid-chem1 $51 \% 3 \mathrm{e} 3.0 . \mathrm{co} ; 2-\mathrm{c}$

36. Antunes LC, Finlay BB (2011) A comparative analysis of the effect of antibiotic treatment and enteric infection on intestinal homeostasis. Gut Microbes 2(2):105-108. https://doi.org/10.4161/ gmic.2.2.15610

37. Bajinka O, Darboe A, Tan Y et al (2020) Gut microbiota and the human gut physiological changes. Ann Microbiol 70:65. https:// doi.org/10.1186/s13213-020-01608-2

38. Bajinka O, Tan Y, Abdelhalim KA, Özdemir G, Qiu X (2020) Extrinsic factors influencing gut microbes, the immediate consequences and restoring eubiosis. AMB Express 10(1):130. https:// doi.org/10.1186/s13568-020-01066-8

39. Bajinka O, Simbilyabo L, Tan Y, Jabang J, Saleem SA (2021) Lung-brain axis. Crit Rev Microbiol. https://doi.org/10.1080/ 1040841X.2021.1960483

40. Liu R, Cheng WJ, Tang HB, Zhong QP, Ming ZP, Dong HF (2019) Comparative metabonomic investigations of Schistosoma japonicum from SCID mice and BALB/c mice: clues to developmental abnormality of Schistosome in the immunodeficient host.
Front Microbiol 10:440. https://doi.org/10.3389/fmicb.2019. 00440

41. Cortés A, Peachey L, Scotti R, Jenkins TP, Cantacessi C (2019) Helminth-microbiota cross-talk - a journey through the vertebrate digestive system. Mol Biochem Parasitol 233:111222. https://doi. org/10.1016/j.molbiopara.2019.111222

42. Yang L, Bajinka O, Jarju PO, Tan Y, Taal AM, Ozdemir G (2021) The varying effects of antibiotics on gut microbiota. AMB Express 11(1):116. https://doi.org/10.1186/s13568-021-01274-w

43. Zhao Y, Yang S, Li B, Li W, Wang J, Chen Z, Yang J, Tan H, Li J (2019) Alterations of the mice gut microbiome via Schistosoma japonicum ova-induced granuloma. Front Microbiol 10:352. https://doi.org/10.3389/fmicb.2019.00352

44. Kay GL, Millard A, Sergeant MJ, Midzi N, Gwisai R, Mduluza T, Ivens A, Nausch N, Mutapi F, Pallen M (2015) Differences in the faecal microbiome in Schistosoma haematobium infected children vs. uninfected children. PLoS Negl Trop Dis 9(6):e0003861. https://doi.org/10.1371/journal.pntd.0003861

45. Zhu X, Chen L, Wu J, Tang H, Wang Y (2017) Salmonella typhimurium infection reduces Schistosoma japonicum worm burden in mice. Sci Rep 7(1):1349. https://doi.org/10.1038/ s41598-017-00992-1

46. Nicholson JK, Connelly J, Lindon JC, Holmes E (2002) Metabonomics: a platform for studying drug toxicity and gene function. Nat Rev Drug Discov 1(2):153-161. https://doi.org/10.1038/ $\operatorname{nrd} 728$

47. Hillier SD, Booth M, Muhangi L, Nkurunziza P, Khihembo M, Kakande M, Sewankambo M, Kizindo R, Kizza M, Muwanga M, Elliott AM (2008) Plasmodium falciparum and helminth coinfection in a semi urban population of pregnant women in Uganda. J Infect Dis 198(6):920-927. https://doi.org/10.1086/591183

48. Liu D, Tan Y, Bajinka O, Wang L, Tang Z (2020) Th17/IL-17 axis regulated by airway microbes get involved in the development of asthma. Curr Allergy Asthma Rep 20(4):11. https://doi.org/10. 1007/s11882-020-00903-x

49. McGeachy MJ, McSorley SJ (2012) Microbial-induced Th17: superhero or supervillain? J Immunol (Baltimore, Md: 1950) 189(7):3285-3291. https://doi.org/10.4049/jimmunol.1201834

50. Sokol H, Pigneur B, Watterlot L, Lakhdari O, Bermúdez-Humarán LG, Gratadoux JJ, Blugeon S, Bridonneau C, Furet JP, Corthier G, Grangette C, Vasquez N, Pochart P, Trugnan G, Thomas G, Blottière HM, Doré J, Marteau P, Seksik P, Langella P (2008) Faecalibacterium prausnitzii is an anti-inflammatory commensal bacterium identified by gut microbiota analysis of Crohn disease patients. Proc Natl Acad Sci USA 105(43):16731-16736. https:// doi.org/10.1073/pnas.0804812105

51. Barnett R (2018) Schistosomiasis. Lancet (London, England) 392(10163):2431. https://doi.org/10.1016/S0140-6736(18) 33008-3

52. Lehman JS Jr, Higashi GI, Bassily S, Farid Z (1972) Rheumatoid factors in Salmonella and Schistosoma infections. Trans R Soc Trop Med Hyg 66(1):125-129. https://doi.org/10.1016/00359203(72)90059-4

53. Osakunor D, Munk P, Mduluza T, Petersen TN, Brinch C, Ivens A, Chimponda T, Amanfo SA, Murray J, Woolhouse M, Aarestrup FM, Mutapi F (2020) The gut microbiome but not the resistome is associated with urogenital schistosomiasis in preschoolaged children. Commun Biol 3(1):155. https://doi.org/10.1038/ s42003-020-0859-7

54. Schneeberger P, Coulibaly JT, Panic G, Daubenberger C, Gueuning M, Frey JE, Keiser J (2018) Investigations on the interplays between Schistosoma mansoni, praziquantel and the gut microbiome. Parasit Vectors 11(1):168. https://doi.org/10.1186/ s13071-018-2739-2

55. Foligné B, Plé C, Titécat M, Dendooven A, Pagny A, Daniel C, Singer E, Pottier M, Bertin B, Neut C, Deplanque D, Dubuquoy 
L, Desreumaux P, Capron M, Standaert A (2019) Contribution of the gut microbiota in P28GST-mediated anti-inflammatory effects: experimental and clinical insights. Cells 8(6):577. https://doi.org/ $10.3390 /$ cells 8060577

\section{Authors and Affiliations}

\section{Ousman Bajinka ${ }^{1,2,5} \cdot$ Mingming Q $^{3} \cdot$ Amadou Barrow $^{4,5} \cdot$ Abdoulie O. Touray $^{6} \cdot$ Lulu Yang $^{1} \cdot$ Yurong Tan $^{1,2,7}$}

1 Department of Microbiology, Central South University, Changsha, Hunan, China

2 China-Africa Research Centre of Infectious Diseases, School of Basic Medical Sciences, Central South University, Changsha 410078, Hunan, China

3 Department of Obstetrics, Zhuzhou Hospital Affiliated to Xiangya School of Medicine, Central South University, Zhuzhou, Hunan, China

4 Heidelberg Institute of Global Health, University Hospital and Medical Faculty, Heidelberg University, Heidelberg, Germany
Publisher's Note Springer Nature remains neutral with regard to jurisdictional claims in published maps and institutional affiliations.
5 School of Medicine and Allied Health Sciences, University of The Gambia, Banjul, The Gambia

6 Division of Experimental Medicine, McGill University, Montreal, Canada

7 Department of Microbiology, Xiangya School of Medicine, Central South University, Changsha 410078, Hunan, China 